\title{
Activation of anion channels in human cells after long term exposure to the marine toxin azaspiracid
}

Andrea Boente-Juncal, Sandra Raposo-García, Celia Costas, M Carmen Louzao, Carmen Vale*, Luis Botana

Departamento de Farmacología, Farmacia y Tecnología Farmacéutica, Facultad de Veterinaria, Universidad de Santiago de Compostela, Lugo, Spain. ${ }^{*}$ Correspondence: mdelcarmen.vale@usc.es; Tel.: +34-982-822-223.

\section{Introduction}

Azaspiracids (AZAs) include a group of marine toxins initially docun group of Netherlands after ingestion of contaminated mussels, harvested in Ireland coasts, by the end of the last century [1-3]. Azaspiracids are produced by dinoflagellates of the gener Azadinium and Amphidoma [4]. The Azesence of AZA toxins in fishery products has been regulated in Europe establishing a limit of $160 \mu \mathrm{g} \mathrm{kg}^{-1}$ AZA equivalents [5]. Thereafter, several acute in vitro studies were performed to elucidate its cellular targets, but the results obtained showed great controversy regarding the possible mechanism of action of AZAs that could contribute to the symptomatology elicited in humans after ingestion of contaminated fishery products. Ou contaminated fishery products. Our
group has recently described that these group has recently described that these toxins partially blocked sodium entry into the cells and caused cytoskeleta alterations [6]. Nevertheless, the effect of azaspiracid on anion channels remains almost completely unexplored [7] Therefore, the main aim of our study was to gain more insight on the effects of AZA on ionic homeostasis using several pharmacological approaches.

\section{Methods}

Chemicals and toxin used

Azaspiracid-1 analogue was purchased from CIFGA (Lugo, Spain) and channel blockers were acquired from Sigma and Tocris.

HEK293 cells expressing the human $\mathrm{Na}_{\mathrm{v}} 1.7$ sodium channel subunit

Immortalized human embryonic kidney cells (HEK293) transfected with the human $\mathrm{Na}_{\mathrm{v}} 1.7$ alpha subunit of the sodium channels were kindly provided under a material transfer agreement with $\mathrm{Dr}$ Andrew Powell (GlaxoSmithKline $R \& D$, Stevenage, UK)

Electrophysiological recordings

Electrophysiological measurements of chloride currents were obtained in wholecell configuration on $\mathrm{Na}_{\mathrm{v}} 1.7 \mathrm{HEK}$ cell line as previously described [6]. Chloride currents $\left(\mathrm{I}_{\mathrm{Cl}}\right)$ were recorded by application of a voltage step protocol from -100 to $+100 \mathrm{mV}$ with $20 \mathrm{mV}$ step

increases and $400 \mathrm{~ms}$ duration.

\section{Results}

Exposure of HEK293 cells to AZA increases voltage-regulated chloride currents $\left(\mathrm{I}_{\mathrm{C}}\right)$ after long-term treatments but had no effect on $\mathrm{I}_{\mathrm{Cl}}$ currents after short term exposure of cells to AZA

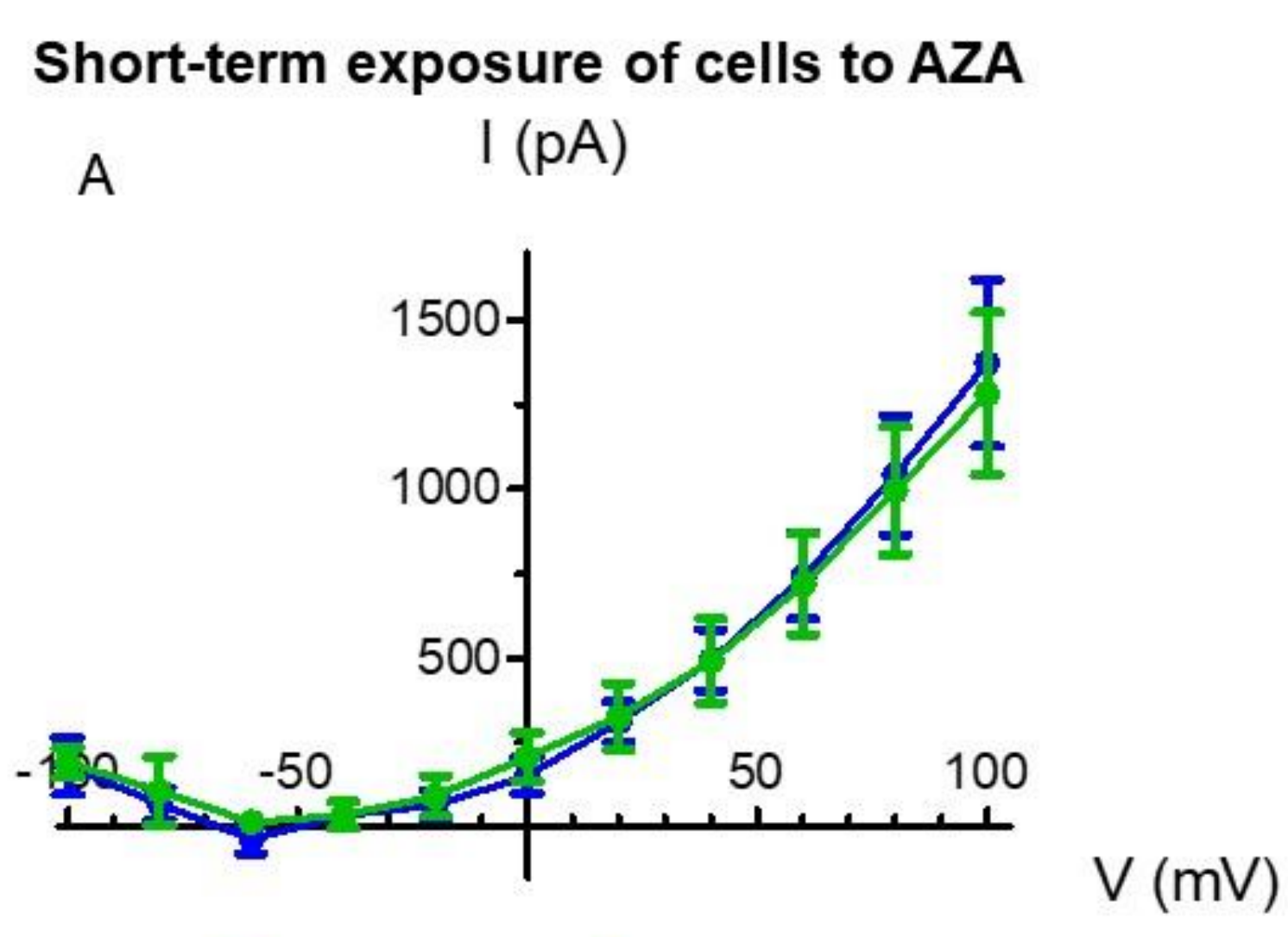

$\rightarrow$ Control $\rightarrow 50$ nM AZA

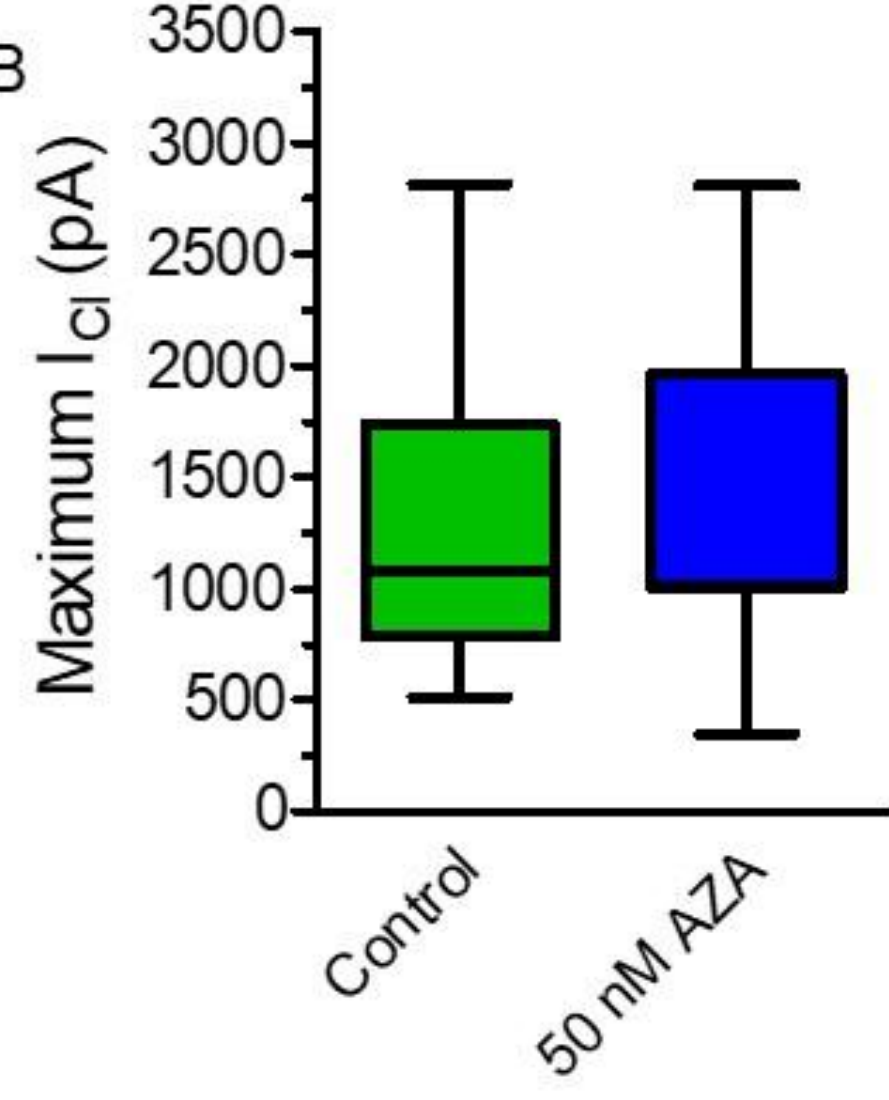

Activation properties of chloride currents evoked from $H E K 293$ cells. (A) Acute exposure of
$H E K 293$ cells to $50 \mathrm{nM}$ AZA did not affect the maximum $I_{C I} \cdot \mathrm{I}-\mathrm{V}$ curve for the chloride curren activation in the absence and presence of toxin. $I_{C}$ were obtained 5 minutes affer bath application

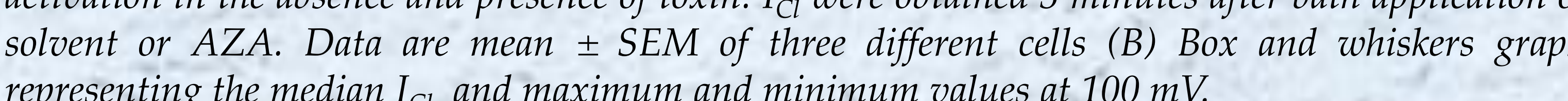

Compilation of channel blockers used to modulate the AZA-induced $\mathrm{I}_{\mathrm{CI}}$ increase in HEK293 cells

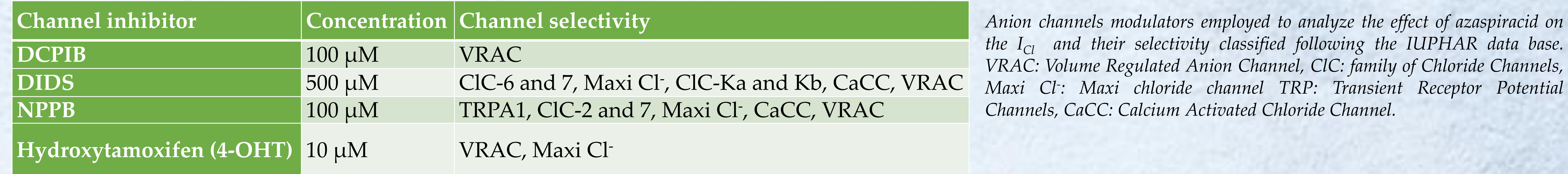

Effect of anion channel blockers on the AZA-induced $\mathrm{I}_{\mathrm{Cl}}$ increase in HEK293 cells
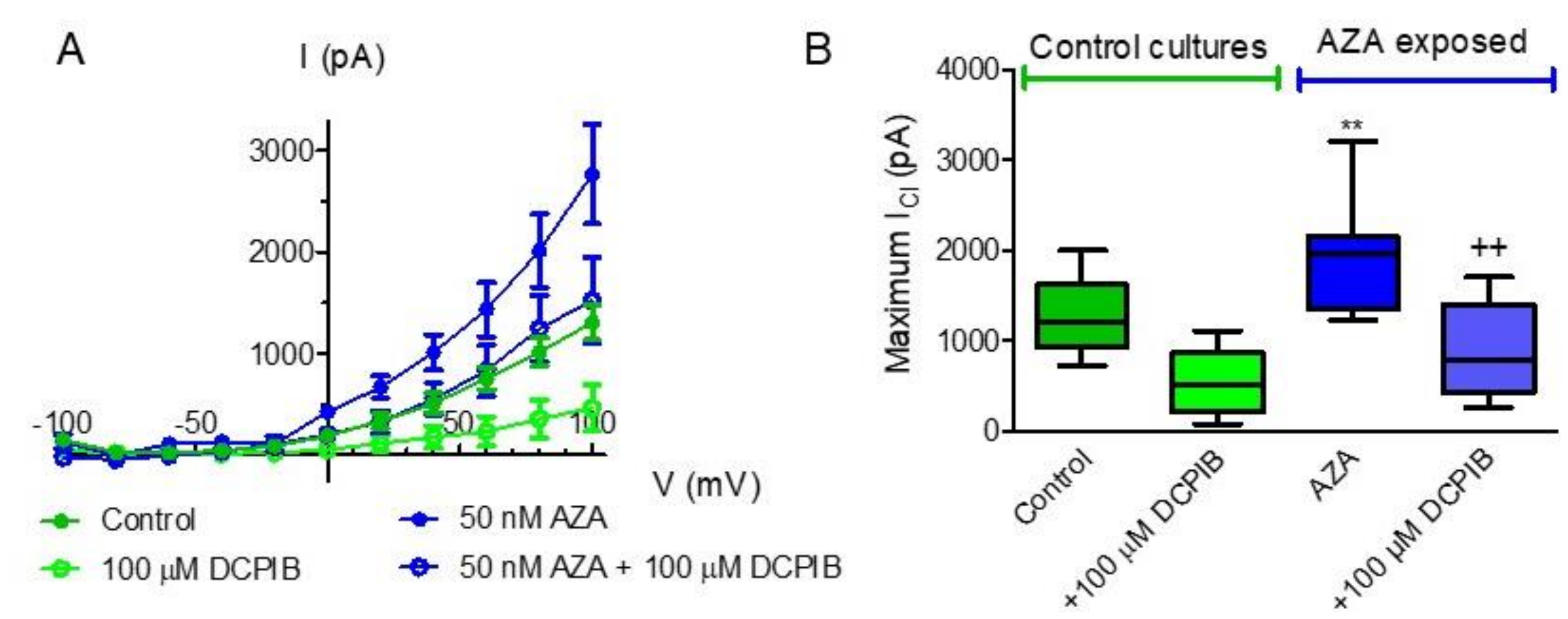

DCPIB decreased chloride currents evoked from HEK cells in control conditions and in cells exposed

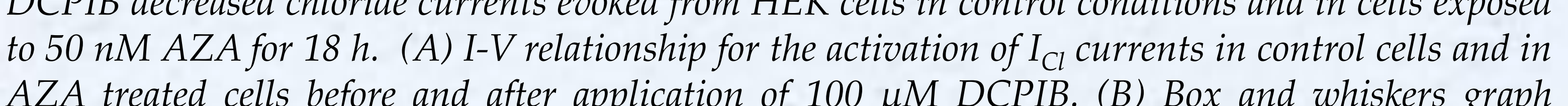
AZA treated cells before and affer application of $100 \mu \mathrm{M} D \mathrm{DCPCPB}$. (B) Box and whickers graph
representing intensities of $I_{c}$ currents at $100 \mathrm{mV}$ in control cells and in cells exposed to AZA in representing intensities of $I_{C C}$ currents at $100 \mathrm{mV}$ in control cells and in cells exposed to AZA int
absence and presence of $100 \mu M \mathrm{DCPIB}$. ${ }^{* *} p<0.01$ vs control currents. $++p<0.01$ vs currents
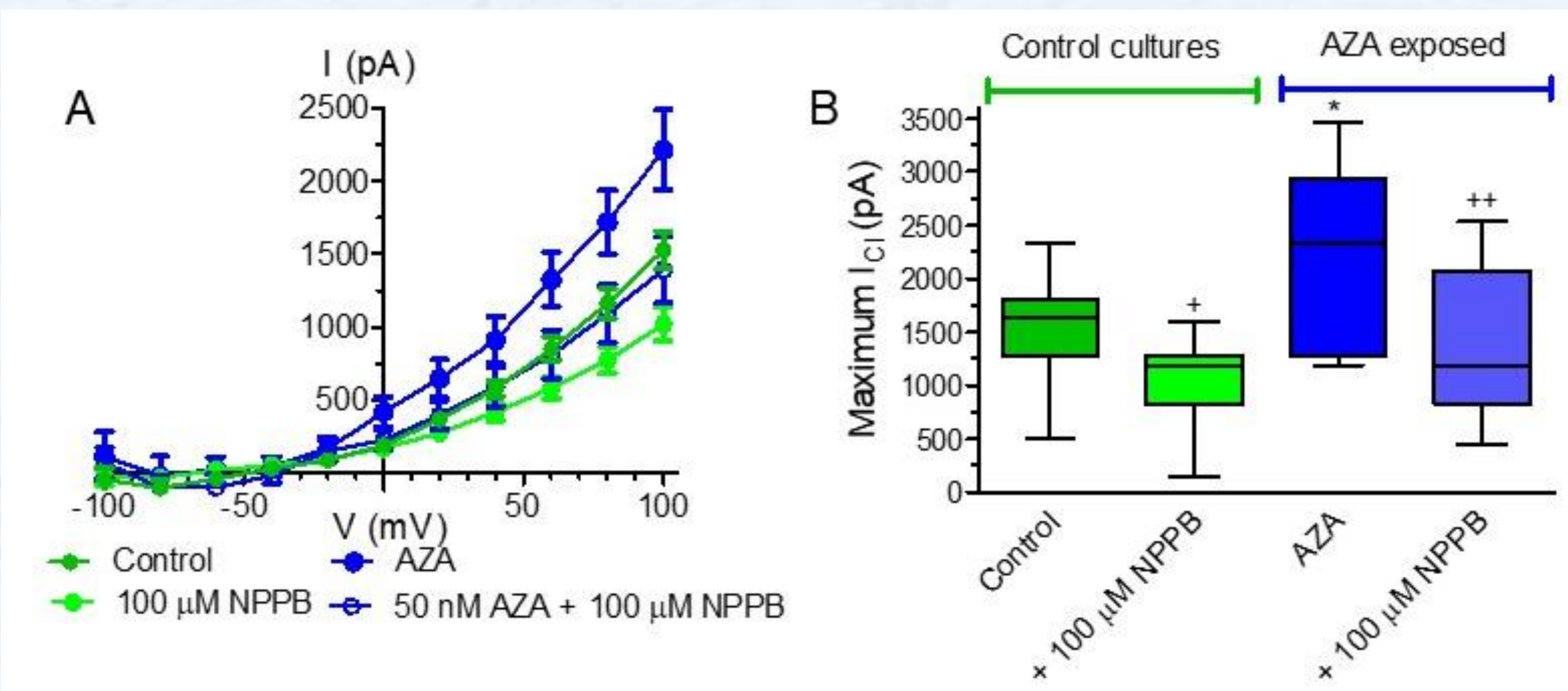

NPPB abolished the chloride currents increase observed in $\mathrm{Na}_{1} 1.7 \mathrm{HEK} 293$ cells after exposition to

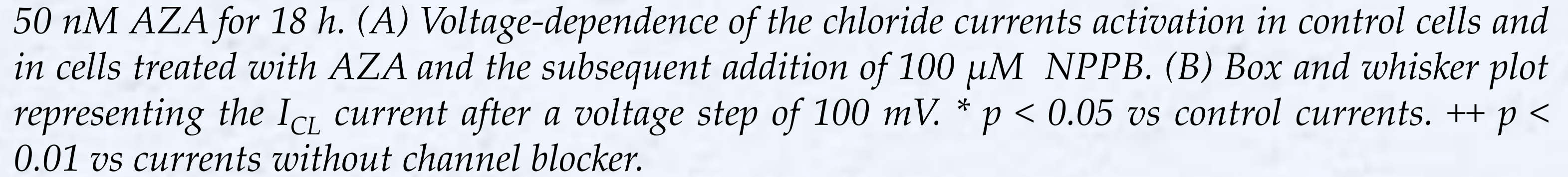
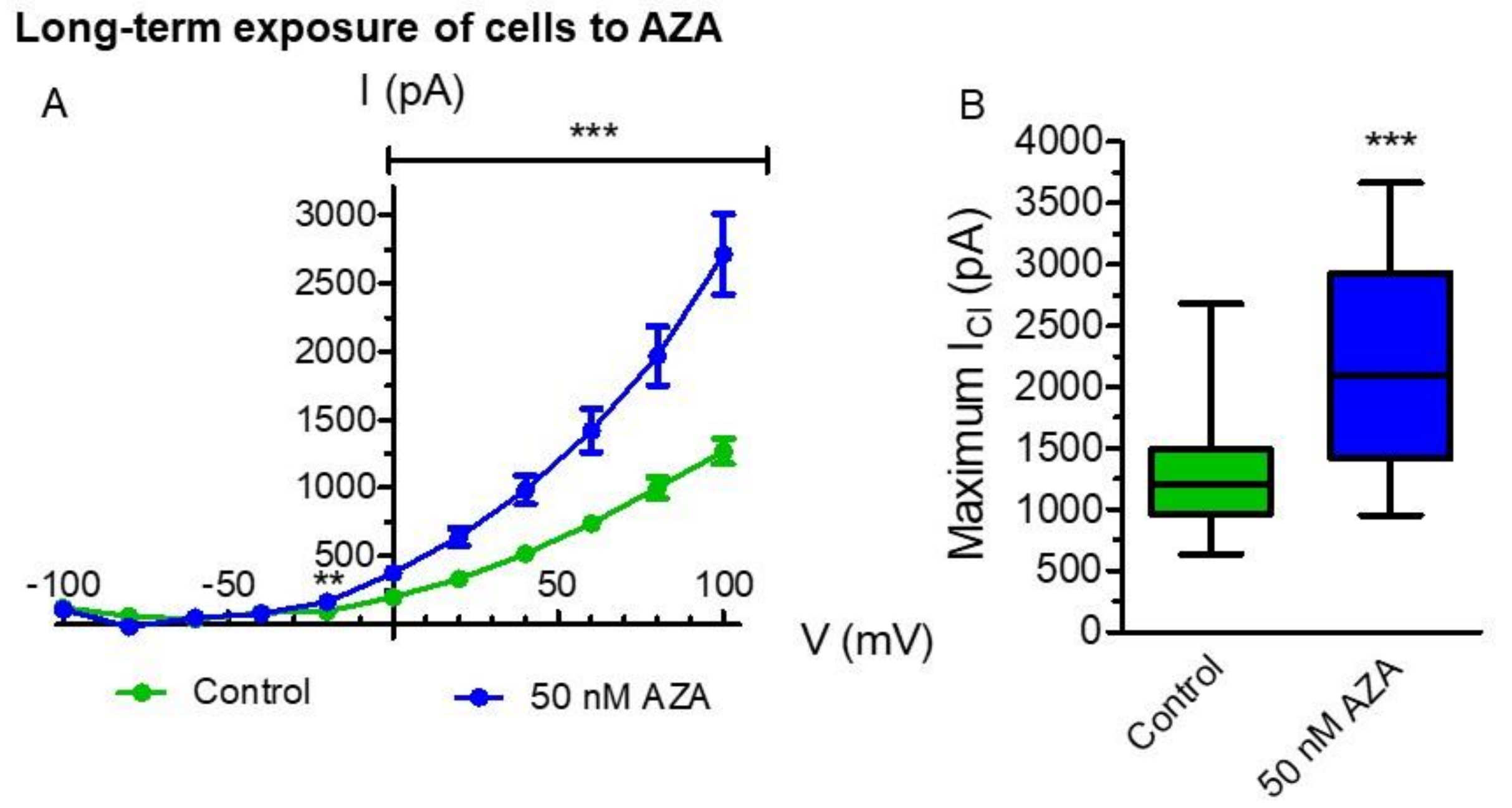

Exposure of HEK293 cells to $50 \mathrm{nM}$ AZA for 18 hours significantly increased $I_{C I}(A) I-V$ curve for the activation of chloride currents in the absence of azaspiracid and after exposure of the cells to
AZA for 18 hours in culture. Data are mean \pm SEM of 27 cells from 9 independent cultures. (B) Boxplot graphs showing the median I I I and maximum and minimum volues 